\title{
EVALUATING ECONOMIC GROWTH EFFICIENCY AND ITS DETERMINANTS UNDER LOW CARBON ECONOMY IN THE CHINESE CONTEXT
}

\author{
LIU, X. ${ }^{1}-$ WEN, T. Q. ${ }^{2}-$ LIU, S. S. ${ }^{3 *}-$ ZHONG, X..$^{{ }^{*}}$ \\ ${ }^{1}$ Institute of Finance, Guangzhou University, Guangzhou 510006, China \\ ${ }^{2}$ Library, Zhongnan University of Economics and Law, Wuhan 430073, China \\ ${ }^{3}$ School of Management, Hubei University of Education, Wuhan 430205, China \\ *Corresponding authors \\ e-mail: liusishi@whut.edu.cn (S.S.Liu); zhongxiong1218@hotmail.com (X. Zhong)
}

(Received 29 ${ }^{\text {th }}$ Dec 2018; accepted $8^{\text {th }}$ Mar 2019)

\begin{abstract}
This research aims to find out effective approaches to improve the low carbon economy efficiency of China and to promote its low carbon economy development. This paper utilizes two kinds of data envelopment analysis models to estimate the economic efficiency and low carbon economy efficiency of China. It takes carbon dioxide emissions as an undesirable output and compares them to find out the different performances of economic growth in various regions in China in the context of low carbon economy development, and then explores the potential determinants of low carbon economy efficiency for different regions in different periods. The results show that low carbon economy efficiency is much lower than economy efficiency in most areas in China. Additionally, both low carbon economy efficiency and economy efficiency show a slow downward trend in most provinces in China from 2000 to 2011, which was followed by a slight increase in 2012. Moreover, low carbon economy efficiency and economy efficiency show obvious geographic characters. We propose some policy implications. Several policy implications are also provided for various areas to improve low carbon economy efficiency.
\end{abstract}

Keywords: economic efficiency, carbon emissions, data envelopment analysis model, low-carbon economy, China

\section{Introduction}

Since the reform and opening-up policies in 1978, China has become the secondlargest economy in the world and seen an average annual economic growth rate of $9.9 \%$ from 1979 to 2010, which arouses the interest of many researchers (Xing et al., 2018; Mutlu et al., 2018). Some of these studies have reported a prolonged slowdown in China's total factor productivity. Many studies calculate the economic efficiency with different data envelopment analysis (DEA) models (Deilmann et al., 2016; Xing et al., 2018), super-efficiency DEA window analysis (Huang et al., 2018a), integrated DEA/AHP model etc. In most of these studies, labor, capital, and energy consumption are used as the inputs, while GDP is used as the output to calculate economic efficiency (Ashraf et al., 2018).

However, the rapid economic growth of China brings about increasingly more energy consumption, which results in rapid increase in $\mathrm{CO}_{2}$ emissions (Dong et al., 2018). China is the largest $\mathrm{CO}_{2}$ emitter in the world which accounts for $26.7 \%$ of global emission in 2012, and consequently, faces significant pressure to reduce carbon emission (Zhang et al., 2014). The carbon intensity goal announced by Chinese government in 2009 shows that the Chinese government pursues the win-win target of GDP growth and carbon emission reduction in the process of economic development. 
However, most previous studies ignored the impact of $\mathrm{CO}_{2}$ emission constraints on the efficiency of China's economic growth (Haque et al., 2019).

Both GDP and $\mathrm{CO}_{2}$ emissions are simultaneously produced in the process of production. However, different from GDP which is a desirable output, carbon emission is an undesirable output. As such, traditional DEA models may not be appropriate. The undesired input can be evaluated by both indirect and direct methods (Scheel, 2001). The former one means using the inverse value of undesirable output as desirable output (Golany and Roll, 1989) or seeing the undesirable output as input (Tyteca, 1997) in standard DEA models. However, the direct approach treats the undesirable outputs more appropriately (Wu et al., 2018). Moreover, the slack-based measure (SBM) model with more desirable outputs and less undesirable outputs relative to fewer inputs should be recognized as efficient (Xie et al., 2018).

Therefore, this paper first estimates the Low Carbon Economy Efficiency of China by taking $\mathrm{CO}_{2}$ emissions as the undesirable output and GDP as the desirable output in the undesirable output DEA model (Kumar et al., 2019). And then, Low Carbon Economy Efficiency with Economy Efficiency is compared to find out the different performances of economic growth in various regions in China in the context of low carbon economy. Moreover, the potential determinants of Low Carbon Economy Efficiency for different regions in different periods are explored to find out the effective ways to improve Low Carbon Economy Efficiency and to promote low carbon economy development (Jeegatheesan et al., 2018).

Plenty of studies contribute to indicate determinants influencing $\mathrm{CO}_{2}$ emissions and economic growth in China. The following factors are of great importance (Suhaili et al., 2018).

(1) Industry structure. In general, industrial is more energy intensive than tertiary industry. It is estimated that the rapid growth of energy consumption and $\mathrm{CO}_{2}$ emissions are consistent with the continuing heavy industrialization in China. In this paper, the proportion of industrial added value in GDP is taken as an indicator for measuring industry structure.

(2) Urbanization. The urbanization rate of China expanded from $36.2 \%$ in 2000 to $52.6 \%$ in 2012 and is estimated to reach 70\% in 2030 (World Bank, 2014). The rapid growth of urbanization rate makes carbon emission reductions very difficult (Song et al., 2018a). In this paper, the proportion of urban population residents in the total population is represented as the urbanization rate (Ali et al., 2018).

(3) Research and Development (R\&D) support. Extensive studies emphasize the importance of R\&D to improve productivity and environmental performance (Song et al., 2018b). Moreover, the literature on climate policy modeling has also indicated the core role that $R \& D$ is playing in industrializing countries such as China because $R \& D$ exerts opposing influences on energy and emission intensities (Huang et al., 2018b). Therefore, the proportion of R\&D expenditure in GDP is taken as a proxy for scientific and technical support (Nordin et al., 2018).

(4) Government support. China is an investment-driven country, as such, the government's attitude towards the environmental problems can be seen from the amount of money invested. In this paper, the proportion of financial expenditure in GDP is considered as a proxy indicator (Majumder et al., 2019).

(5) International trade. The ongoing raising of international trade is a significant driver for GDP growth and carbon dioxide emissions in China (Xu et al., 2017). It is estimated that $\mathrm{CO}_{2}$ emissions in trade accounted for $19 \%$ of its total production-based 
emissions in 2008 (Zhang, 2014) due to more exports of energy-intensive products. The ratio of the amount of imports and exports to GDP is taken as a proxy indicator in this paper. Table 1 shows the details of these indicators.

Table 1. Summary of determinants of low carbon economy efficiency

\begin{tabular}{c|c|c|c|c}
\hline Factors & Max & Min & Mean & S.D \\
\hline The proportion of industrial added value in GDP (IS) & 0.530 & 0.134 & 0.395 & 0.080 \\
Urbanization rate (UR) & 0.893 & 0.232 & 0.468 & 0.149 \\
Gross domestic expenditure on R\&D in GDP (RD) & 0.429 & 0.001 & 0.024 & 0.068 \\
The proportion of financial expenditure in GDP (GS) & 0.612 & 0.069 & 0.177 & 0.079 \\
The ratio of imports and exports to GDP (IE) & 1.632 & 0.026 & 0.316 & 0.367 \\
\hline
\end{tabular}

The objective of this research is to find out effective approaches to improve the low carbon economy efficiency of China and to promote its low carbon economy development. The remainder of this paper is organized as follows. 2 different DEA models are employed to estimate Economy Efficiency and Low Carbon Economy Efficiency, as well as their inputs and outputs, are briefly introduced (Nouaim et al., 2019). Afterwards, the paper presents and discusses in details the results of Economy Efficiency and Low Carbon Economy Efficiency from the viewpoint of different regions in various periods in China. Conclusions and several policy implications can be found in the last section.

\section{Materials and methods}

\section{DEA models}

As one of the most widely used efficiency evaluation methods, DEA models provide a mechanism for measuring relative efficiency of similar economic production systems. Different DEA models and their applying requirements and advantages have been discussed in details by Wu et al. (2018), Liu and Liu (2016) and Jiang et al. (2016). In this paper, BCC DEA model is employed to estimate Economy Efficiency which aims at constant inputs producing more outputs (GDP). In contrast, undesirable output DEA model is utilized to estimate Low Carbon Economy Efficiency, which implies that constant inputs producing more desirable output (GDP) and fewer undesirable output $\left(\mathrm{CO}_{2}\right.$ emissions $)$.

\section{BCC DEA model}

BCC DEA model was first proposed by Banker et al. (1984) and largely applied in the situation of "variable returns to scale" (VRS). BCC DEA model can classify the DMUs into efficient and inefficient ones according to the rule that whether the efficiency score equals one.

According to Banker et al. (1984), the envelopment form of BCC DEA model can be expressed as Equation 1: 


$$
\begin{gathered}
\theta^{*}=\operatorname{Min}\left(\theta-\varepsilon\left(e^{-} S^{-}+e^{+} S^{+}\right)\right) \\
\text {s.t. }\left\{\begin{array}{l}
\sum_{j=1}^{n} X_{j} \lambda_{j}+S^{-}=\theta X_{0} \\
\sum_{j=1}^{n} Y_{j} \lambda_{j}-S^{+}=Y_{0} \\
\sum_{j=1}^{n} \lambda_{j}=1 \\
\lambda, S^{+}, S^{-} \geq 0
\end{array}\right.
\end{gathered}
$$

where $X_{j}$ and $Y_{j}$ in the model respectively represent inputs and outputs of the $j^{\text {th }}$ DMU, $\lambda_{j}$ denotes the weights, $\theta$ is technological efficiency, $\theta<1$ means the DMU is inefficient, while $\theta=1$ shows the DMU is efficient in BCC DEA.

\section{Undesirable output SBM DEA model}

Based on Tone (2001) and Zhou et al. (2006), the undesirable output SBM DEA model can be defined as follows.

Given that there are $n$ DMUs in production system $P$, and each DMU has $m$ inputs, $s_{1}$ desirable outputs, and $s_{2}$ undesirable outputs.

$$
X=\left[x_{1}, x_{2}, \ldots, x_{n}\right] \in R^{m \times n}, Y^{g}=\left[y_{1}^{g}, y_{2}^{g}, \ldots, y_{n}^{g}\right] \in R^{s_{1} \times n} \text { and } Y^{b}=\left[y_{1}^{b}, y_{2}^{b}, \ldots, y_{n}^{b}\right] \in R^{s_{2} \times n}
$$

Matrices represent inputs, desirable outputs and undesirable outputs respectively. Moreover, $X>0, Y^{g}>0$, and $Y^{b}>0$. The production possibility set $(P)$ is defined as:

$$
P=\left\{\left(x, y^{g}, y^{b}\right) \mid x \geq X \lambda, y^{g} \leq Y^{g} \lambda, y^{b} \geq Y^{b} \lambda, \sum \lambda=1\right\}
$$

where $\lambda \in R^{n}$ is the intensity vector, and $\sum \lambda=1$ represents the assumption of variable returns to scale (VRS).

We suppose that the $\operatorname{DMU}_{0}\left(x_{0}, y_{0}^{g}, y_{0}^{b}\right)$ is efficient if there is no vector $\left(x, y^{g}, y^{b}\right) \in P$ that simultaneously satisfies $x_{0} \geq x, y_{0}^{g} \leq y^{g}$ and $y_{0}^{b} \geq y^{b}$. And the SBM DEA models with undesirable outputs can be written as

$$
\begin{gathered}
\rho=\operatorname{Min} \frac{1-\frac{1}{m} \sum_{i=1}^{m} \frac{s_{i}^{s-}}{x_{i 0}}}{1+\frac{1}{s_{1}+s_{2}}\left(\sum_{r=1}^{s_{1}} \frac{s_{r}^{g}}{y_{r 0}^{g}}+\sum_{r=1}^{s_{2}} \frac{s_{r}^{b}}{y_{r 0}^{b}}\right)} \\
\text { s.t. }\left\{\begin{array}{l}
x_{0}-X \lambda-s^{-}=0 \\
y_{0}^{g}-Y^{g} \lambda+s^{g}=0 \\
y_{0}^{b}-Y^{b} \lambda-s^{b}=0 \\
s^{-} \geq 0, s^{g} \geq 0, s^{b} \geq 0, \lambda \geq 0
\end{array}\right.
\end{gathered}
$$


where, $s^{-}, s^{g}$ and $s^{b}$ correspond to slack variables of inputs, desirable outputs, and undesirable outputs respectively. The objective function is strictly decreasing with respect to $s_{i}^{-}(\forall i), s_{r}^{g}(\forall r), s_{r}^{b}(\forall r)$ and the objective value satisfies $0<\rho \leq 1$. Let the optimal solution of the above program be $\left(\lambda^{*}, s^{-*}, s^{g^{*}}, s^{b^{*}}\right)$, and if and only if $\rho=1$, $s^{-*}=0, s^{g^{*}}=0$ and $s^{b^{*}}=0$, the DMU is efficient.

Using the transformation by Charnes and Cooper (1962), the equivalent linear program of Equation 1 can be obtained to calculate efficiency scores.

\section{Data for inputs and outputs}

The empirical study covers 30 provinces in the Chinese mainland, excluding Tibet because of energy consumption data loss. The 30 provinces in China can be aggregated to four areas, the Eastern (E), Northeast (NE), Central (C) and Western (W) areas. The Eastern area is the richest and most developed region in China. The Northeast area is one of the earliest and most important industrial base in the country. The Central area is considered to be a connecting link between the booming Eastern region and the relatively poor Western region by the Chinese government. The Western area is relatively backward but the resource-rich region.

The amount of energy consumption (E), labor force (L), and capital stock (K) are taken as inputs in both DEA models. Moreover, GDP is considered as the only output in BCC DEA model and the desirable output in undesirable DEA model, which presents the performance of economic development. In addition, the amount of $\mathrm{CO}_{2}$ emissions is taken as the undesirable output in the undesirable DEA model, which reflects the objective to reduce carbon emissions.

\section{$\mathrm{CO}_{2}$ emissions}

The amount of $\mathrm{CO}_{2}$ emissions of different types of fossil fuel can be calculated. According to the national standard from the National Development and Reform Commission (NDRC) (Guidance for Compiling Provincial Greenhouse Gas Emission Lists (Trial), 2011), eight types of fossil fuel are considered, including coal, coke, crude, gasoline, kerosene, diesel oil, fuel oil, and natural gas. Thus, according to the approach recommended by IPCC (2006), $\mathrm{CO}_{2}$ emissions from fossil fuel burning can be calculated based on

$$
Q_{\mathrm{CO}_{2}}=\sum_{i=1}^{8} Q_{i} \times N C V_{i} \times C E F_{i} \times C O F_{i} \times(44 / 12)
$$

where $Q_{\mathrm{CO}_{2}}$ is the quantity of $\mathrm{CO}_{2}$ emissions from all eight types of fossil fuel consumption; $i$ represents different types of fossil fuel, $Q_{i}$ is the total consumption of fuel ${ }^{i} ; N C V_{i}, C E F_{i}$ and $C O F_{i}$ represent the default net calorific value, carbon content factor, and carbon oxidization factor of fuel $i$; $N C V_{i} \times C E F_{i} \times C O F_{i} \times(44 / 12)$ is $\mathrm{CO}_{2}$ emission factor of fuel $i$. All these data can be got from NDRC as shown in Table 2.

All the data on fossil fuel are compiled from China Statistical Yearbook. However, the latest China Statistical Yearbook 2013 only provides energy consumption data by fuel by provinces in the year of 2011. As a consequence, we estimated these data in 2012 using the average annual growth rate of 2000-2011. Thus, the amount of $\mathrm{CO}_{2}$ 
emissions for each province can be calculated by Equation 3 and the descriptive statistics are shown in Figure 1.

Table 2. $\mathrm{CO}_{2}$ emission factors by fuel

\begin{tabular}{c|c|c|c|c|c|c|c|c}
\hline Fuel & Coal & Coke & Crude & Fuel oil & Gasoline & Kerosene & Diesel & Natural gas \\
\hline$N C V(\mathrm{~kJ} / \mathrm{kg})$ & 20908 & 28435 & 41816 & 41816 & 43070 & 43070 & 42652 & 38931 \\
$C E F($ tonne $\mathrm{C} / \mathrm{TJ})$ & 26.37 & 29.5 & 20.1 & 21.1 & 18.9 & 19.5 & 20.2 & 15.3 \\
$C O F$ & 0.94 & 0.93 & 0.98 & 0.98 & 0.98 & 0.98 & 0.98 & 0.99 \\
Emission factor $k_{i}$ & 1.9003 & 2.8604 & 3.0202 & 3.1705 & 2.9251 & 3.0179 & 3.0959 & 2.1622 \\
\hline
\end{tabular}

The unit of $k_{i}$ is $\mathrm{kg}-\mathrm{CO}_{2} / \mathrm{kg}$ except natural gas, which is $\mathrm{kg}-\mathrm{CO}_{2} / \mathrm{m}^{3}$

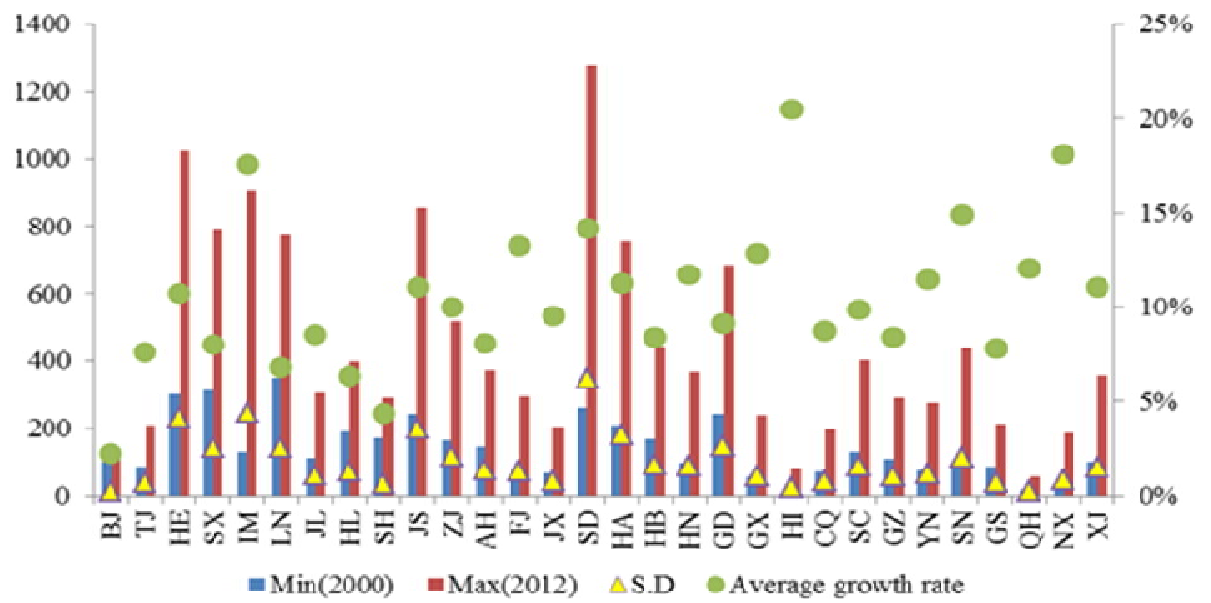

Figure 1. Total amount of $\mathrm{CO}_{2}$ emissions for 30 provinces in China (million tons)

\section{Summary of inputs and outputs}

The data on E, L, and GDP are obtained from China Statistical Yearbook. Data for K from 2000 to 2006 are directly acquired from Shan (2008), and the rest of the data from 2007 to 2012 are estimated by perpetual inventory method according to Shan (2008). Considering the fact that Chongqing used to be a part of Sichuan Province before 1997, Shan (2008) estimated their K value on the basis that considering Chongqing still as part of Sichuan. In order to separate the two different regions, $\mathrm{K}$ is divided according to gross fixed capital formation in these two provinces. All price values are converted to 2000 prices according to GDP deflator. Table 3 shows descriptive statistics of the input and output variables by region.

\section{Analysis of impact factors}

To further discover the determinants influencing China's economic growth efficiency under carbon emissions constraint, regression analysis method for panel data is applied to measure the relationship between the efficiency and the impact factors mentioned in 2.2.2. Specifically, the econometric model can be defined as:

$$
L C E E_{i, t}=C+C_{i}+\beta_{1} * I S_{i, t}+\beta_{2} * U R_{i, t}+\beta_{3} * R D_{i, t}+\beta_{4} * G S_{i, t}+\beta_{5} * I E_{i, t}+\varepsilon_{i, t}
$$


where, $L C E E_{i, t}$ is carbon efficiency of province $i$ in year $t$. IS, UR, RD, GS, IE represent the five determinants mentioned before, $C$ is a common intercept, $C_{i}$ represents the individual effect, $C+C_{i}$ indicates the varying efficiency among different provinces, $\varepsilon_{i, t}$ is the error term.

Table 3. Summary statistics of input and output variables by region (2000-2012)

\begin{tabular}{|c|c|c|c|c|c|c|c|c|c|c|}
\hline \multirow{3}{*}{ Region } & \multicolumn{6}{|c|}{ Inputs } & \multirow{2}{*}{\multicolumn{2}{|c|}{$\begin{array}{c}\text { Output } \\
\text { GDP } \\
(100 \text { million USD })\end{array}$}} & \multirow{2}{*}{\multicolumn{2}{|c|}{$\begin{array}{c}\begin{array}{c}\text { Undesirable } \\
\text { output }\end{array} \\
\mathrm{CO}_{2}(100 \text { million } \\
\text { tonnes) }\end{array}$}} \\
\hline & \multicolumn{2}{|c|}{ E (100 Mtce) } & \multicolumn{2}{|c|}{ K (100 million USD) } & \multicolumn{2}{|c|}{ L (1 million) } & & & & \\
\hline & Mean & SD & Mean & SD & Mean & SD & Mean & SD & Mean & SD \\
\hline E_BJ & 57.32 & 10.61 & 2756.249 & 1262.043 & 10.07 & 2.54 & 100.3045 & 35.91916 & 120.65 & 13.76 \\
\hline E_TJ & 48.25 & 17.11 & 1891.827 & 1362.055 & 4.56 & 0.54 & 60.34284 & 28.67891 & 136.27 & 39.37 \\
\hline E_HE & 207.91 & 65.58 & 4063.016 & 2601.682 & 35.74 & 1.87 & 144.9277 & 53.2488 & 607.43 & 225.32 \\
\hline C_SX & 133.49 & 37.97 & 2071.075 & 1556.405 & 15.27 & 0.96 & 62.70013 & 26.46932 & 569.19 & 138.01 \\
\hline W_IM & 110.56 & 54.25 & 2673.29 & 2467.961 & 10.86 & 0.89 & 70.20476 & 40.61602 & 417.28 & 237.79 \\
\hline NE_LN & 158.13 & 45.09 & 3454.778 & 2433.889 & 20.24 & 1.69 & 126.6616 & 50.07473 & 526.93 & 138.47 \\
\hline NE_JL & 63.46 & 18.20 & 2184.257 & 1793.164 & 11.48 & 0.85 & 58.7078 & 25.20205 & 191.20 & 60.86 \\
\hline NE_HL & 88.42 & 22.35 & 1858.744 & 1067.398 & 16.83 & 0.69 & 77.80098 & 24.09578 & 269.91 & 69.53 \\
\hline E_SH & 87.15 & 21.13 & 3450.929 & 1494.084 & 8.43 & 1.02 & 126.7916 & 37.54386 & 229.29 & 35.72 \\
\hline E_JS & 182.27 & 69.92 & 7431.195 & 4755.302 & 41.00 & 4.92 & 278.0748 & 117.1187 & 494.09 & 192.97 \\
\hline E_ZJ & 127.22 & 39.67 & 4941.707 & 2779.458 & 33.42 & 4.86 & 193.6125 & 71.19288 & 327.55 & 113.74 \\
\hline C_AH & 74.30 & 20.37 & 2261.005 & 1489.445 & 36.19 & 2.50 & 84.56416 & 35.16442 & 235.35 & 72.67 \\
\hline E_FJ & 69.52 & 25.75 & 2710.772 & 1808.361 & 19.33 & 2.10 & 102.3354 & 38.79931 & 154.96 & 71.54 \\
\hline C_JX & 46.68 & 15.67 & 1807.2 & 1267.894 & 21.43 & 1.66 & 63.65722 & 27.85474 & 127.13 & 43.49 \\
\hline E_SD & 250.61 & 94.26 & 7677.597 & 4827.992 & 51.69 & 3.97 & 268.8539 & 107.6881 & 744.34 & 334.36 \\
\hline C_HA & 157.52 & 54.20 & 5033.007 & 3872.653 & 57.54 & 2.45 & 156.9017 & 63.60701 & 450.71 & 175.46 \\
\hline C_HB & 111.26 & 37.15 & 3167.432 & 2131.834 & 28.20 & 3.38 & 106.5139 & 47.12221 & 273.47 & 88.24 \\
\hline C_HN & 102.63 & 42.22 & 2572.21 & 1809.053 & 37.23 & 2.25 & 106.7428 & 47.37182 & 219.89 & 85.48 \\
\hline E_GD & 194.25 & 68.14 & 6641.326 & 3890.437 & 48.52 & 7.62 & 324.8159 & 117.0079 & 429.23 & 141.29 \\
\hline W_GX & 54.96 & 21.23 & 2149.302 & 1822.175 & 27.34 & 1.59 & 64.10032 & 27.88576 & 119.16 & 56.64 \\
\hline E_HI & 9.86 & 3.79 & 546.5904 & 309.1981 & 3.92 & 0.45 & 14.41257 & 5.550566 & 35.29 & 22.25 \\
\hline W_CQ & 54.17 & 22.55 & 1502.283 & 792.4238 & 17.67 & 1.23 & 54.5722 & 23.56849 & 116.55 & 42.80 \\
\hline W_SC & 130.22 & 45.85 & 2943.216 & 1607.141 & 46.85 & 2.37 & 117.2177 & 49.52972 & 254.64 & 86.15 \\
\hline W_GZ & 65.13 & 16.37 & 1186.849 & & 22.34 & 1.36 & 31.99477 & & 185.77 & 56.29 \\
\hline W_YN & 64.77 & 21.37 & 1729.01 & 1175.067 & 25.43 & 2.07 & 52.83377 & 19.43141 & 176.38 & 64.35 \\
\hline W_SN & 62.59 & 23.86 & 2415.456 & 1896.651 & 19.06 & 0.62 & 65.09878 & 32.83076 & 224.19 & 110.49 \\
\hline W_GS & 46.72 & 12.60 & 872.2084 & 572.9711 & 13.35 & 0.85 & 29.27414 & 11.08636 & 139.13 & 39.20 \\
\hline W_QH & 19.00 & 7.92 & 422.3674 & 317.9981 & 2.71 & 0.23 & 8.944712 & 4.144462 & 31.97 & 12.85 \\
\hline W_NX & 27.47 & 10.51 & 596.5249 & 503.7929 & 3.04 & 0.21 & 10.68166 & 5.416159 & 91.10 & 46.81 \\
\hline W_XJ & 62.23 & 22.50 & 1506.54 & 962.5757 & 7.81 & 0.77 & 38.53641 & 14.59276 & 192.47 & 82.70 \\
\hline Northeast & 310.00 & 85.40 & 7497.779 & 5291.441 & 48.56 & 3.11 & 263.1704 & 99.2544 & 988.04 & 268.55 \\
\hline Eastern & 1234.36 & 414.70 & 42111.21 & 25034.48 & 256.67 & 29.40 & 1614.472 & 611.2801 & 3279.10 & 1183.08 \\
\hline Central & 625.88 & 206.74 & 16911.93 & 12122.06 & 195.86 & 12.39 & 581.0799 & 246.8879 & 1875.75 & 595.65 \\
\hline Western & 697.84 & 258.26 & 17997.05 & 12910.5 & 196.47 & 11.99 & 543.4562 & 242.996 & 1948.64 & 826.84 \\
\hline
\end{tabular}

E, NE, C, and W represent Eastern, Northeast, Central and Western area of China respectively. BJ: Beijing, TJ: Tianjin, HE: Hebei, SX: Shanxi, IM: Inner Mongolia, LN: Liaoning, JL: Jilin, HL: Heilongjiang, SH: Shanghai, JS: Jiangsu, ZJ: Zhejiang, AH: Anhui, FJ: Fujian, JX: Jiangxi, SD: Shandong, HA: Henan, HB: Hubei, HN: Hunan, GD: Guangdong, GX: Guangxi, HI: Hainan, CQ: Chongqing, SC: Sichuan, GZ: Guizhou, YN: Yunnan, SN: Shannxi, GS: Gansu, QH: Qinghai, NX: Ningxia, XJ: Xinjiang 
The results of Hausman test indicates Fixed Effects estimator should be taken in this study. As such, the estimated coefficients between Low Carbon Economy Efficiency and determinants can be calculated according to Equation 4 by Eviews software. As a calculation result, the estimated coefficients by region are shown in Table 4.

Table 4. The estimated coefficients in Table 1 by region

\begin{tabular}{c|c|c|c|c|c}
\hline & Whole country & Eastern & Northeast & Central & Western \\
\hline IS & $-0.625^{* * *}$ & $-1.470^{* * *}$ & 0.025 & $-1.247^{* * *}$ & 0.516 \\
UR & $0.677^{* * *}$ & $0.763^{* * *}$ & -0.128 & -0.137 & $2.074^{* * *}$ \\
RD & $-0.195^{*}$ & $-5.559^{* * *}$ & $9.000^{*}$ & $-0.240^{* * *}$ & $-13.653^{* * *}$ \\
GS & $0.593^{* * *}$ & $-1.135^{* *}$ & $-0.916^{*}$ & $1.483^{* * *}$ & $0.981^{* * *}$ \\
IE & $0.282^{* * *}$ & $0.241^{* * *}$ & $-0.278^{* *}$ & -0.292 & -0.011 \\
C & $0.379^{* * *}$ & $1.060^{* * *}$ & $0.725^{* * *}$ & $0.877^{* * *}$ & $-0.531^{* * *}$ \\
Observations & 390 & 130 & 39 & 104 & 117 \\
Adj R2 & 0.619 & 0.75 & 0.677 & 0.692 & 0.624 \\
D.W. & 1.945 & 2.264 & 2.232 & 2.862 & 2.573 \\
\hline
\end{tabular}

$* * *, * * *$ indicates $1 \%, 5 \%$, and $10 \%$ significant, respectively

(1) The dependence on the proportion of industrial added value in GDP (IS) has a negative influence on Low Carbon Economy Efficiency in the whole country, which agrees with most research (Hao and Peng, 2017). The high proportion of energy intensive industry in the secondary industry accounts for a large amount of carbon emissions in China (Fan et al., 2018). However, IS has a negative effect on the Eastern and Central areas but a positive effect on the Northeast and Western area. For the Eastern and Central area, the desirable output GDP is huge and presents an upward trend, so the core task of promoting Low Carbon Economy Efficiency improving should be concentrated on carbon abatement. However, in the Northeast and Western area, where the economics are relative backwardness, industrial structure which shifts from industrial to other industries will damage economic growth rather than decrease carbon emissions.

(2) Urbanization rate (UR) is one of the most vital positive factors impact Low Carbon Economy Efficiency of the whole country, as well as the Eastern and Western areas. Low Carbon Economy Efficiency in these areas will respectively go up by $0.677 \%, 0.763 \%, 2.074 \%$ with the value of UR increase $1 \%$. The fast growing UR in Eastern area can promote the concentration of population lives and improve the efficiency of public infrastructure. Therefore, economies of scale of energy consumption can improve the energy efficiency. For the Western area, where the intensity of population is much smaller than the Eastern, the economies of scale of energy consumption are much more obvious. Therefore, a positive correlation can be seen in UR and Low Carbon Economy Efficiency there. However, UR had a negative and non-significant effect on the Northeast and Central areas. The reason is that with the process of urbanization, residents in urban have a growing demand for higher levels of energy services as living standards rise, which should greatly promote the total energy consumption and ultimately promote $\mathrm{CO}_{2}$ emissions.

(3) The ratio of R\&D expenditure to GDP (RD) contributes to Low Carbon Economy Efficiency in China was negative for every area but the Northeast. Firstly, energy 
rebound effect can be seen in these areas. Energy rebound effect means that although technological innovations improved the energy efficiency and energy savings, it also promoted rapid economic development and resulted in energy consumption increasing, and the volumes of increased over that of decreased. Secondly, R\&D expenditure in China, which covers all aspects of science and technology, should be improved both in volume and structure.

(4) The relationship between the proportion of financial expenditure in GDP (GS) and Low Carbon Economy Efficiency is positive except for the Eastern and Northeast areas. The amount of investment in financial expenditure such as environmental pollution treatment seeing a continuing increase in recent years, which showed the efforts and determination of the government to reduce energy overuse and waste. However, it can be seen from Table 5 that the government's efforts are negative in the Eastern and Northeast areas. For one thing, the amount of the investment may not be enough, especially for the Eastern area with the largest GDP in China; for another, investing in subsidy of equipment and technologies using have not been effectively used.

Table 5. The estimated coefficients in Table 1 by period

\begin{tabular}{c|c|c|c|c|c|c|c|c|c|c}
\hline & \multicolumn{2}{|c|}{ Whole Country } & \multicolumn{2}{c|}{ Eastern } & \multicolumn{2}{c|}{ Northeast } & \multicolumn{2}{c|}{ Central } & \multicolumn{2}{c}{ Western } \\
\hline & $\mathbf{0 0 - 0 7}$ & $\mathbf{0 8 - 1 2}$ & $\mathbf{0 0 - 0 7}$ & $\mathbf{0 8 - 1 2}$ & $\mathbf{0 0 - 0 7}$ & $\mathbf{0 8 - 1 2}$ & $\mathbf{0 0 - 0 7}$ & $\mathbf{0 8 - 1 2}$ & $\mathbf{0 0 - 0 7}$ & $\mathbf{0 8 - 1 2}$ \\
\hline$I S$ & $-0.885^{* * *}$ & -0.035 & $-1.850^{* * *}$ & -0.414 & $0.478^{* *}$ & 0.481 & $-1.421^{* * *}$ & $-1.372^{* * *}$ & $-2.451^{* * *}$ & $2.035^{* * *}$ \\
$U R$ & $0.586^{* * *}$ & $1.321^{* * *}$ & $0.963^{* * *}$ & 0.607 & $-2.106^{* * *}$ & 1.766 & $0.857^{* *}$ & -0.247 & $2.190^{* * *}$ & $0.706^{* * *}$ \\
$R D$ & -0.204 & -0.276 & $-6.600^{* * *}$ & -0.871 & 3.250 & -7.324 & $-36.953^{* * *}$ & $-10.908^{* *}$ & 0.134 & -0.195 \\
$G S$ & $0.671^{* * *}$ & $0.724^{* * *}$ & $-2.881^{* * *}$ & 0.942 & $0.415^{* * *}$ & 1.121 & -1.147 & $-0.484^{* *}$ & $1.832^{*}$ & 1.521 \\
$I E$ & $0.299^{* * *}$ & $0.229^{* * *}$ & $0.242^{* * *}$ & $0.235^{* * *}$ & 0.244 & -0.416 & 0.144 & 0.886 & $-0.577^{* * *}$ & 0.241 \\
$C$ & $0.532^{* * *}$ & $-0.261^{*}$ & $1.305^{* * *}$ & 0.338 & 1.347 & -0.756 & $1.151^{* * *}$ & $1.335^{* * *}$ & 0.340 & $-1.074^{* * *}$ \\
Obs & 240 & 150 & 80 & 50 & 24 & 15 & 48 & 30 & 88 & 55 \\
Adj $R^{2}$ & 0.673 & 0.718 & 0.867 & 0.708 & 0.634 & 0.613 & 0.656 & 0.791 & 0.666 & 0.736 \\
$D . W$. & 2.074 & 2.200 & 2.290 & 2.358 & 2.386 & 2.042 & 1.591 & 2.349 & 2.115 & 2.629 \\
\hline
\end{tabular}

$* * *, * *, *$ indicates $1 \%, 5 \%$, and $10 \%$ significant respectively

(5) The ratio of imports and exports to GDP (IE) has a positive impact on Low Carbon Economy Efficiency of China. International trade can impact Low Carbon Economy Efficiency through introducing advanced technology, equipment, and management experience, as well as embodied carbon (Kang et al., 2018). The former factors' effects can be seen from a long horizon while the latter can be seen in the initial stage of IE development. It can be seen that IE showed a positive and significant relationship with Low Carbon Economy Efficiency in the Eastern area where the vast majority of imports and exports in China are produced. The other three areas only account for $13.03 \%$ of the total amount of imports and exports in China from 2000 to 2012, and the majority of export-oriented factories in these areas are transferred from the Eastern area because of high energy consumption and environmental pollution. These factories contribute much more carbon emissions rather than GDP. International trade in these three areas was still in the initial stage and saw a negative impact on Low Carbon Economy Efficiency. 
Moreover, this paper divides the period of 2000-2012 into two periods (2000-2007 and 2008-2012) to discover different determinants affecting Low Carbon Economy Efficiency of different areas in different periods. The results are shown in Table 5.

(1) IS sees decreased negative affect on Low Carbon Economy Efficiency in all areas except the Northeast, which means that energy and resource saving during the process of industrialization should be taken into account. However, increased positive correlation between IS and Low Carbon Economy Efficiency still can be seen in the Northeast area, for the reason that as an old industry base in China, industrialization is the basis of economic development in the Northeast area. Consequently, they should promote Low Carbon Economy Efficiency improvement during the process of industrialization through means of upgrading the industrial production from high investment, high energy consumption and high emissions to low investment, low energy consumption, and low emissions.

(2) Urbanization shows a further strengthened positive impact on Low Carbon Economy Efficiency improvement in the whole country and the Northeast area, while decreased affection in other three areas. Especially for the Central area, urbanization shows a negative impact on Low Carbon Economy Efficiency in the period of 2008-2012. The average annual growth rate of urbanization in the Central area rose from $1.46 \%$ in the period of 2000-2007 to $1.6 \%$ in the period of 2008-2012, with an increase of $0.14 \%$, while the Eastern, Northeast and Western areas seeing an increase of $0.5 \%, 0.16 \%, 0.3 \%$ respectively. The change of average annual growth rate of urbanization in the Central area is the smallest and the rate in the Northeast area is the slowest, where UR has a positive impact on improving economic efficiency under carbon emissions constraints. The results indicate that pursuing the urbanization speed while ignoring its quality should be avoided in the process of urbanization.

(3) RD showed a slightly increased negative impact on Low Carbon Economy Efficiency in the whole country while greatly decreased negative effect on the Eastern and Central areas, and became a negative factor in the period of 2008-2012 in the Northeast and Western areas. Besides the reason of volumes and structure of R\&D expenditure mentioned above, the different performances of $\mathrm{RD}$ in various areas in China also contribute to these differences. The growth rate of RD in the whole country, Eastern and Central areas increased by $38.11 \%, 44.39 \%$ and $57.52 \%$ from the period of $2000-2007$ to 2008-2012. However, the Northeast and Western areas only saw $14.83 \%$ and $17.87 \%$ increase, less than a half comparing with other areas.

(4) Government support plays an increasingly more important role in improving Low Carbon Economy Efficiency in all areas but the Western. These results indicate that local governments paying more attention to the development of Low Carbon Economy Efficiency, and implying the importance of government support in the initial stage of low carbon economy development. However, for a small amount of financial expenditure in the Western area (198.82 billion per year per provinces in 2008-2012, only accounts for $78.27 \%$ of that in the whole country), the importance of government support is not obvious.

(5) International trade can be seen a decreased correlation with Low Carbon Economy Efficiency in the whole country, Eastern and Northeast areas in these two periods, especially for the Northeast area where the coefficient turned from positive in 2000-2007 to negative in 2008-2012. However, the correlation between Low Carbon Economy Efficiency and IE went up from $0.144,-0.577$ to 0.886 and 0.241 in the Central and Western areas at the same time. The reason is that imports and exports can be seen a 
decreased importance in these two areas. Although the amount of imports and exports increased by 2.3 and 2.6 times per province in the Central and Western areas from the period of 2000-2007 to 2008-2012, the proportion in GDP dropped from 10\% to $9.74 \%$ in the Central area and slightly increased from $11.12 \%$ to $11.49 \%$ in the Western area. For the Eastern, Northeast, and the whole country, the amount of imports and exports increased by $1.67,1.57$ and 1.72 times, while the proportion in GDP decreased from $84.3 \%, 27.89 \%$, $56 \%$ to $72.64 \%, 22.73 \%, 49.43 \%$.

\section{Results}

With the two different DEA models, both Economy Efficiency and Low Carbon Economy Efficiency of different regions from 2000 to 2012 can be calculated. The calculation results show that the majority of provinces in China saw a smaller Low Carbon Economy Efficiency than Economy Efficiency except for Guangdong, Shanghai, Beijing, Tianjin, Hainan, Qinghai, and Ningxia. Jiangsu, Zhejiang, Shandong, Chongqing and Sichuan witnessed an upward trend in both Low Carbon Economy Efficiency and Economy Efficiency. In contrast, both the Low Carbon Economy Efficiency and Economy Efficiency declined in Inner Mongolia, Jilin and Guangxi. Although Low Carbon Economy Efficiency in Hainan and Qinghai pointed at efficiency frontier (the score of Low Carbon Economy Efficiency is one), their Economy Efficiency showed a downward trend, which implied poor economic conditions there. However, most provinces demonstrate gradually increased Low Carbon Economy Efficiency with declined Economy Efficiency after 2007, when the Chinese government proposed the first national plan and policy-based document National Climate Chang Program on climate changes.

As shown in Table 6, the majority of provinces in the Eastern area are high-efficiency regions, and most provinces in the Central and Western area of China are low efficiency. These results imply that the Low Carbon Economy Efficiency shows obvious geographic characters. Furthermore, the whole period can be divided into four periods, as shown in Table 7.

Table 6. Average efficiency scores and rank by region (2000-2012)

\begin{tabular}{c|c|c|c|c|c|c|c|c|c}
\hline \multirow{2}{*}{ Regions } & \multicolumn{2}{|c|}{ EE } & \multicolumn{2}{c|}{ LCEE } & \multirow{2}{*}{ Regions } & \multicolumn{2}{c|}{ EE } & \multicolumn{2}{c}{ LCEE } \\
\cline { 2 - 4 } & Score & Ranking & Score & Ranking & & Score & Ranking & Score & Ranking \\
\hline Northeast (NE) & 0.808 & & 0.550 & & Central (C) & 0.771 & & 0.780 & 0.505 \\
Eastern (E) & 0.892 & & 0.843 & & Western (W) & 0.644 & & 0.660 & 0.550 \\
China & 0.777 & & 0.638 & & & & & & \\
\hline
\end{tabular}

LCEE - low carbon economy efficiency; EE - economy efficiency

Table 7. Regional economic efficiency by period

\begin{tabular}{c|c|c|c|c|c|c|c|c}
\hline & \multicolumn{2}{|c|}{$\mathbf{9}^{\text {th }}$ Plan (2000) } & \multicolumn{2}{c|}{$\mathbf{1 0}^{\text {th }}$ Plan (2001-05) } & \multicolumn{2}{|c|}{$\mathbf{1 1}^{\text {th }}$ Plan (2006-10) } & $\mathbf{1 2}^{\text {th }}$ Plan (2011-12) \\
\hline & EE & LCEE & EE & LCEE & EE & LCEE & EE & LCEE \\
\hline China & 0.812 & 0.674 & 0.791 & 0.651 & 0.763 & 0.623 & 0.760 & 0.627 \\
Northeast (NE) & 0.859 & 0.559 & 0.829 & 0.571 & 0.789 & 0.540 & 0.779 & 0.517 \\
Eastern (E) & 0.897 & 0.860 & 0.900 & 0.851 & 0.886 & 0.831 & 0.884 & 0.842 \\
Central (C) & 0.828 & 0.537 & 0.797 & 0.524 & 0.762 & 0.492 & 0.761 & 0.479 \\
Western (W) & 0.716 & 0.613 & 0.669 & 0.562 & 0.642 & 0.528 & 0.653 & 0.542 \\
\hline
\end{tabular}


China's Economy Efficiency had decreased from 0.812 in 2000 to 0.76 in the 12 th five-year with a percentage decline of $6.38 \%$. The Western area saw its efficiency rising from 0.642 in the 11 th five-year to 0.653 in the 12 th five-year, while the other three areas saw downward trends. China's Low Carbon Economy Efficiency had gradually decreased from 0.674 in the period of 9 th five-year to 0.623 in the period of 11 th fiveyear, and then slightly increased to 0.627 in the period of 12th five-year. Seeing the same trends as the whole country, Low Carbon Economy Efficiency of the Eastern and Western areas experienced a slight rise in the period of 12th five-year, while the Northeast and Central area had declined from $0.559,0.537$ in 2000 to $0.517,0.479$ in the 12th five-year. Comparing Economy Efficiency with Low Carbon Economy Efficiency, it can be found that Low Carbon Economy Efficiency is smaller than Economy Efficiency in any areas at any time.

\section{Discussion}

The analytical methodology of this paper is innovative and can be utilized in similar research. It utilizes two kinds of data envelopment analysis models to estimate the economic efficiency and low carbon economy efficiency of China. It takes carbon dioxide emissions as an undesirable output and compares them to find out the different performances of economic growth in various regions in China in the context of low carbon economy development, and then explores the potential determinants of low carbon economy efficiency for different regions in different periods.

As can be seen in the previous section, it is still a long and tough journey for China to achieve the win-win goal of high GDP growth and low $\mathrm{CO}_{2}$ emissions, for Low Carbon Economy Efficiency is lower than Economy Efficiency in most provinces in China, which means unbalanced development of high GDP growth and low $\mathrm{CO}_{2}$ emissions, and implied that most policy makers and implementers prefer increasing desirable output of GDP than decreasing undesirable output of $\mathrm{CO}_{2}$ emissions. This is because provincial leaders in China pay more emphasis on the quantity of GDP growth over the quality of economic performance because the likelihood of promotion of them increases with GDP growth in their provinces (Chen et al., 2017). Therefore, the quality of economics development, such as carbon emissions, should be considered as the next goal to achieve after getting a high value of GDP. This conclusion has also been supported by the evidence that the richest Eastern area also has the highest Low Carbon Economy Efficiency in China. Consequently, it is necessary to reform the performance evaluation system of policy maker and implementers from the quantity of economic growth to the quality of economic performance. Therefore, the environment protection, energy efficiency, as well as resources and other indicators, should be considered as important as GDP in the performance evaluation system, so as to stimulate policy makers and implementers to take decreasing undesirable outputs equally important as increasing desirable outputs.

Moreover, Low Carbon Economy Efficiency and its determinants vary with regions in China. As a consequence, different provinces should implement different policies and actions based on their actual situation to improve the Low Carbon Economy Efficiency. Provinces in the most developed and richest Eastern area see the highest Low Carbon Economy Efficiency for higher levels of environmental concern than other areas (Lin and $\mathrm{Xu}, 2018$ ). Also, they have sufficient economic strength to realize the balanced development of GDP growth and $\mathrm{CO}_{2}$ emissions. Provinces in the Western area have 
the advantage of the natural ecological environment and benefit from more stringent constraints of promoting GDP growth due to the requirements to protect the natural ecological environment. Therefore, the core task for eastern and western areas to improve Low Carbon Economy Efficiency is expected to maintain a balance between GDP growth and $\mathrm{CO}_{2}$ emissions. In addition, the reason that the Northeast and Central area saw a continuing decrease Low Carbon Economy Efficiency in recent years is that these two areas emphasis on increasing the desirable output GDP while ignoring the reduction of undesirable output $\mathrm{CO}_{2}$ emissions. Consequently, the Northeast and Central regions need to treat carbon emissions abatement as important as GDP growth, which can be promoted through the reform of performance evaluation system for policy makers and implementers. In addition, different policies and actions have different effects on Low Carbon Economy Efficiency of various areas. For the Northeast area, the likelihood of promoting efficiency increases with RD, while RD has a negative impact on the Eastern and Western areas. For the Eastern and Western areas, the process of urbanization is more critical to improving Low Carbon Economy Efficiency, they should emphasize the quality of urbanization. Government support, especially financial support, sees more positive and obvious impact for the Central area.

Finally, it is necessary to introduce market-based policy instruments to simultaneously control $\mathrm{CO}_{2}$ emissions and promote GDP growth. Both the central and local governments play key roles in promoting economic development in China, through the ways of making policy, planning, resources input and allocation and so on (McMillan and Naughton, 1992). However, according to the law of diminishing marginal returns, expanding the volume of production factors input would yield lower per-unit returns at some time, which means relying on factors-driven to promote economic development is unsustainable and possibly increasing $\mathrm{CO}_{2}$, so as to exacerbate the difficulty of economic efficiency improvement. As a result, marketbased policy tools, such as environmental tax and emissions trading, should be introduced to provide incentives for carbon emitters to reduce carbon emissions without damaging economic development. For one thing, the revenue from environmental taxes can be reallocated to investment in energy saving technologies, or expanding the amount of funds invested in environmental pollution control, so as to promote Low Carbon Economy Efficiency improvement. For another, emissions permit trading is also a financial instrument. Several carbon emission trading systems such as EUETS and CCX introduced a series of financial derivative products (Helm, 2014). The purpose of developing emission trading market not only can control carbon emissions but also can be used as a financial instrument to promote the development of the financial market.

\section{Conclusions}

Improving the efficiency of economic development is of vital importance of China to achieve sustainable development, and $\mathrm{CO}_{2}$ emissions impact the development of economics as well. This research compared two kinds of economics development efficiency based on whether considering $\mathrm{CO}_{2}$ emissions or not (Economy Efficiency or Low Carbon Economy Efficiency). Furthermore, we analyzed in details that the determinants of Low Carbon Economy Efficiency of different areas in China. The following basic conclusions can be obtained:

(1) There is still a long and tough journey for China to achieve the win-win goal of high GDP growth and low $\mathrm{CO}_{2}$ emissions. 
(2) Low Carbon Economy Efficiency and its determinants vary with regions in China.

(3) It is necessary to introduce market-based policy instruments to simultaneously control $\mathrm{CO}_{2}$ emissions and promote GDP growth.

Most importantly, the analytical methodology of this paper is innovative and can be utilized in similar research.

Acknowledgements. This work is funded by the National Natural Science Foundation of China (No. 71601148 and 71271159), the China Postdoctoral Science Foundation (No. 2016M592393), and the Projects of the Social Science Foundation of Guangdong Province (No. GD16YYJ02).

\section{REFERENCES}

[1] Ali, A. J., Akbar, N. J., Arun Kumar, M. S., Vijayakumar, S., Akbar John, B. (2018): Effect of cadmium chloride on the haematological profiles of the freshwater ornamental fish, Cyprinus carpio Koi (Linnaeus, 1758). - Journal Clean Was 2(2): 10-15.

[2] Ashraf, M. A., Hanafiah, M. M. (2018): Sustaining life on earth system through clean air, pure water, and fertile soil. - Environmental Science \& Pollution Research

[3] Banker, R. D., Charnes, A., Cooper, W. W. (1984): Some models for estimating technical and scale inefficiencies in data envelopment analysis. - Management Science 30(9): 1078-1092.

[4] Charnes, A., Cooper, W. W. (1962): Programming with linear fractional functionals. Naval Research Logistics 9(3-4): 181-186.

[5] Chen, W., Chen, J., Xu, D., Liu, J., Niu, N. (2017): Assessment of the practices and contributions of China's green industry to the socio-economic development. - Journal of Cleaner Production 153(1): 648-656.

[6] Deilmann, C., Lehmann, I., Reißmann, D., Hennersdorf, J. (2016): Data envelopment analysis of cities - investigation of the ecological and economic efficiency of cities using a benchmarking concept from production management. - Ecological Indicators 67: 798806.

[7] Dong, K., Sun, R., Dong, X. (2018): $\mathrm{CO}_{2}$ emissions, natural gas and renewables, economic growth: assessing the evidence from China. - Science of the Total Environment 640: 293-302.

[8] Fan, J. L., Wang, J. D., Kong, L. S., Zhang, X. (2018): The carbon footprints of secondary industry in China: an input-output subsystem analysis. - Natural Hazards 91(2): 635-657.

[9] Golany, B., Roll, Y. (1989): An application procedure for DEA. - Omega 17: 237-250.

[10] Hao, Y., Peng, H. (2017): On the convergence in China's provincial per capita energy consumption: new evidence from a spatial econometric analysis. - Energy Economics 68: 31-43.

[11] Haque, D. M. E., Hayat, T., Tasnim, S. (2019): Time series analysis of subsidence in Dhaka City, Bangladesh using Insar. - Malaysian Journal of Geosciences 3(1): 32-44.

[12] Helm, D. (2014): The European framework for energy and climate policies. - Energy Policy 64(1): 29-35.

[13] Huang, J., Liu, Q., Cai, X., Hao, Y., Lei, H. (2018a): The effect of technological factors on China's carbon intensity: new evidence from a panel threshold model. - Energy Policy 115: 32-42.

[14] Huang, J., Xia, J., Yu, Y., Zhang, N. (2018b): Composite eco-efficiency indicators for china based on data envelopment analysis. - Ecological Indicators 85: 674-697.

[15] Jegatheesan, J., Zakaria, Z. (2018): Stress analysis on pressure vessel. - Environment \& Ecosystem Science 2(2): 53-57. 
[16] Jiang, W., Liu, J., Liu, X. (2016): Impact of carbon quota allocation mechanism on emissions trading: an agent-based simulation. - Sustainability 8(8).

[17] Kang, Z. Y., Li, K., Qu, J. Y. (2018): The path of technological progress for China's lowcarbon development: evidence from three urban agglomerations. - Journal of Cleaner Production 178: 644-654.

[18] Kumar, P., Joshi, V. (2019): A geospatial- statistical approach to alienate priority area of upper watershed of River Subarnarekha using morphometric assessment framework. Malaysian Journal of Geosciences 3(1): 21-31.

[19] Lin, B., Xu, M. (2018): Regional differences on $\mathrm{CO}_{2}$, emission efficiency in metallurgical industry of China. - Energy Policy 120: 302-311.

[20] Liu, X., Liu, J. (2016): Measurement of low carbon economy efficiency with a threestage data envelopment analysis: a comparison of the largest twenty $\mathrm{CO}_{2}$ emitting countries. - International Journal of Environmental Research and Public Health 13(11): 1116.

[21] Majumder, S. C., Islam, K., Hossain, M. M. (2019): State of research on carbon sequestration in Bangladesh: a comprehensive review. - Geology, Ecology, and Landscapes 3(1): 29-36. DOI: 10.1080/24749508.2018.1481656

[22] McMillan, J., Naughton, B. (1992): How to reform a planned economy: lessons from China. - Oxford Review of Economic Policy 8(1): 130-143.

[23] Mutlu, C. C., Essen, M. V., Peng, M. W., Saleh, S. F., Duran, P. (2018): Corporate governance in China: a meta $\square$ analysis. - Journal of Management Studies 55(6): 943-979.

[24] Nordin, N. F. H., Tg Mahassan, T. S. H., Chowdhury, A. J. K. (2018): Bacterial population study in oil-contaminated and uncontaminated soils. - Journal Clean Was 2(2): 06-09.

[25] Nouaim, W., Chakiri, S., Rambourg, D., Karaoui, I., Ettaqy, A., Chao, J., Allouza, M., Razoki, B., Yazidi, M., El Hmidi, F. (2019): Mapping the water erosion risk in the Lakhdar river basin (central High Atlas, Morocco). - Geology, Ecology, and Landscapes 3(1): 22-28. DOI: 10.1080/24749508.2018.1481655

[26] Scheel, H. (2001): Undesirable outputs in efficiency valuations. - European Journal of Operational Research 132: 400-410.

[27] Shan, H. J. (2008): Re-estimating the capital stock of China: 1952-2006. - The Journal of Quantitative \& Technical Economics 25(10): 17-31.

[28] Solomon, S. (Ed.) (2007): Climate Change 2007-the Physical Science Basis: Working Group I Contribution to the Fourth Assessment Report of the IPCC. Volume 4. Cambridge University Press, Cambridge, UK.

[29] Song, C. J., Liu, Q. L., Gu, S., Wang, Q. (2018a): The impact of China's urbanization on economic growth and pollutant emissions: an empirical study based on input-output analysis. - Journal of Cleaner Production 198: 1289-1301.

[30] Song, M., Wang, S., Sun, J. (2018b): Environmental regulations, staff quality, green technology, R\&D efficiency, and profit in manufacturing. - Technological Forecasting \& Social Change 133: 1-14.

[31] Suhaili, M. Z., Samsudin, M. D. M. (2018): Utilization of wastewater for corrosion prevention of carbon steel pipe using single chamber microbial fuel cells. - Environment \& Ecosystem Science 2(2): 47-52.

[32] Tone, K. (2001): A slacks-based measure of efficiency in data envelopment analysis. European Journal of Operational Research 130: 498-509.

[33] Tyteca, D. (1997): Linear programming models for the measurement of environmental performance of firms-concepts and empirical results. - Prod Analysis 8: 183-197.

[34] World Bank, DRC. China: A new approach for efficient, inclusive, sustainable urbanization. - http://www.worldbank.org/en/news/press-release/2014/03/25/china-anew-approach-for-efficient-inclusive-sustainable-urbanization. 
[35] Wu, X., Chen, Y., Guo, J., Gao, G. (2018): Inputs optimization to reduce the undesirable outputs by environmental hazards: a DEA model with data of PM2.5 in China. - Natural Hazards 90(1): 1-25.

[36] Xie, B. C., Wang, J. Y., Ma, J. J., Duan, N. (2018): Efficiency evaluation of china's provincial power systems based on the dynamic network slacks-based measure model. Journal of Cleaner Production 174: 650-660.

[37] Xing, Z. C., Wang, J. G., Zhang, J. (2018): Expansion of environmental impact assessment for eco-efficiency evaluation of China's economic sectors: an economic input-output based frontier approach. - Science of the Total Environment 635: 284-293.

[38] Xu, J., Zhang, M., Zhou, M., Li, H. (2017): An empirical study on the dynamic effect of regional industrial carbon transfer in China. - Ecological Indicators 73: 1-10.

[39] Zhang, B., Chen, G. Q., Li, J. S., Tao, L. (2014): Methane emissions of energy activities in China 1980-2007. - Renewable and Sustainable Energy Reviews 29(0): 11-21.

[40] Zhou, P., Ang, B. W., Poh, K. L. (2006): Slacks-based efficiency measures for modeling environmental performance. - Ecological Economics 60: 111-118. 